\title{
In memory of Giulio Giordano
}

\author{
R. Cordera ${ }^{1} \cdot$ P. Del Monte ${ }^{1} \cdot$ D. Ferone ${ }^{1} \cdot$ M. Giusti $^{1} \cdot$ M. Marugo $^{1}$
}

(C) Italian Society of Endocrinology (SIE) 2020

Giulio Giordano, professor emeritus of Endocrinology, was born in Ortona (a small town in Abruzzo) on October 31, 1927. He passed away in Genova on March 18, 2020. He is survived by his wife, three sons and two grandchildren.

He attended classic high school in Ortona and in 1945, after surviving the famous WW2 battle of Ortona (December 20-28 1943), he moved to Genoa, travelling for days by foot, train and other occasional means, where he began the Medical School. He was a brilliant student and graduated in Medicine cum laude and silver medal in 1951, discussing an experimental thesis on internal medicine.

He was interested in internal medicine with a special interest in endocrinology. During the following years he accepted a job as assistant professor in Medicine. In 1977 he was appointed as professor of Endocrinology and chief of the Clinical Endocrine Unit, till his retirement in 1999.

$\mathrm{He}$ practiced medicine and endocrinology, with a special focus on GH disorders. His research interest was directed broadly to endocrinology, in a time when the scientific approach was changing from personal experience and observation to rigorous methodology. He greatly contributed to the creation of facilities, clinical laboratory and nuclear medicine services to carry on rigorous research. He had also teaching responsibility and directed the Program in Endocrinology and trained dozens of graduate and post graduate students. He played an important role on organization and development of Endocrinology in Italy eventually serving as President of Società Italiana di Endocrinologia. He authored many scientific articles, reviews, and manuals.

Giulio Giordano was a "maestro" of many clinicians and scientist: he always recommended scientific and moral integrity. After retirement he continued to be interested in endocrinology with a particular attention to our work. His passion for soccer prompted him to organize a "endocrine championship" to be held in the occasion of the meetings of Società Italiana di Endocrinologia in Genoa (1992).

He was also a supporter of two soccer teams Juventus and Sampdoria. In the last years he became interested in science and religion and leaves an almost finished book on religion, science and society interaction.

Funding Not applicable.

\section{Compliance with ethical standards}

Conflict of interest Not applicable.

Ethics approval Not applicable.

Consent to participate Not applicable.

Consent for publication Not applicable.

Availability of data and material Not applicable.

Code availability Not applicable.

Publisher's Note Springer Nature remains neutral with regard to jurisdictional claims in published maps and institutional affiliations.
R. Cordera

record@unige.it

1 Endocrine and Diabetologic Units, University of Genova, viale Benedetto XV no. 6, 16100 Genoa, Italy 